\title{
LA DISTANCIA DE LA CULTURA EMPRESARIAL CON CHINA: UNA APROXIMACIÓN PARA EL EMPRESARIO ESPAÑOL
}

\author{
Autora: Joaquin Amat Royo ${ }^{1}$ \\ Profesor en la Escuela Superior de Comercio Internacional \\ Universidad Pompeu Fabra
}

\section{Resumen}

Tras su incorporación a la economía de mercado hace menos de 20 años, China ya se ha convertido en el primer exportador mundial. Su especial atractivo en costes y mercado potencial han propiciado que se convierta en el primer receptor de inversiones extranjeras. La cultura China y la compleja interacción con empresas occidentales ha generado distorsiones en las relaciones empresariales, entre ellas con las empresas españolas. El artículo analiza las diferencias entre la cultura española y china en un ámbito empresarial, utilizando los métodos de análisis de autores con modelos especializados en la comparación multicultural. Las conclusiones recogen sugerencias que permiten entender los fundamentos

\footnotetext{
${ }^{1}$ jamat@jooaquinamat.com
} 
culturales y servir de hoja de ruta al empresario español en sus operaciones en China, facilitando de este modo la gestión intercultural.

Palabras clave: gestión intercultural; distancia cultural; cultura china.

\title{
Business Culture's Distance With China: An approach to the Spanish bu- sinessman
}

\begin{abstract}
The recent addition of China's market economy less than 20 years ago, has already become the world's biggest exporter. Its special appeal in costs and potential market have led it to become the first recipient of international foreign investment. Chinese culture and the complex interaction with Western companies has created distortions in business relationships, including with Spanish companies. The article discusses the differences between Spanish and Chinese culture in a business environment, by using methods of analysis from authors with specialized models in multicultural comparison. Conclusions gather suggestions helping to understand the cultural principles and serving as a roadmap for the Spanish entrepreneur operating in China, thereby facilitating cross-cultural management.
\end{abstract}

Key words: intercultural management; cultural distance; chinese culture.

Recibido: 30/03/2016

Aceptado: 19/07/2016

\section{SITUACIÓN ACTUAL}

Según Ghemawat, "Las empresas exageran de manera habitual el atractivo de los mercados extranjeros y puede dar lugar a errores costosos" (Ghemawat, 2001:1).

China ha experimentado un rápido crecimiento económico debido fundamentalmente a dos motivos que se han retroalimentado: la inversión de capital, tanto procedente de las elevadas tasas de ahorro interno como de inversión extranjera y el rápido aumento de la productividad.

El informe "Global Manufacturing Competitiveness Index" (Deloitte, 2015) indica que China mantiene el primer puesto en el ranking de competitividad del Informe, tras seis años ocupando el mismo puesto de liderazgo en el ranking. El 
que fue a principio de siglo XX un país atractivo para inversores extranjeros, principalmente por sus bajos costes laborales, se ha convertido en el líder mundial en Competitividad Global de Producción, donde se valoran Factores tan diversos como la Formación, Productividad Laboral, Red de Suministradores, Marco Legal, Infraestructura Educativa, Infraestructuras de Transporte, Atractivo del Mercado Local, etc., entre otros.

A pesar de que España ha sido el cuarto país inversor a nivel mundial, su presencia en China es escasa comparada con otros países occidentales, ello se debe principalmente a que la internacionalización de las empresas españolas ha ido por detrás de los principales países europeos que vieron en Asia su atractivo y potencial, mientras que España se centraba y era atraída por la Unión Europea debido a las bajas barreras técnicas y comerciales como atractivo principal, relegándose la acción internacional fuera de la Unión Europea, entre otros motivos a las distancias geográficas, económicas y administrativas, pero especialmente a una "lejanía cultural acusada" (Cacho,2006:56), que también se manifiesta en Asia en general (Fanjul, 2016).

A pesar del atractivo del país, para las inversiones productivas y de servicios, surgen barreras culturales que dificultan tremendamente la gestión intercultural entre empresas chinas y españolas.

Existen ejemplos ilustrativos conocidos de empresas españolas que se han retirado de China, como Irizar, Telepizza, Joyería Tous, Desigual y otras que han reducido substancialmente su presencia como Supermercados Dia que se ha replegado a la zona de Shanghai o el BBVA que mantiene una pequeña participación meramente financiera en el CITIC.

El presente artículo pretende identificar los aspectos culturales relevantes y diferenciales a que debe enfrentarse el empresario español con actividades en China. Tales diferencias constituyen barreras que pueden justificar la escasa tradición histórica reciente del empresariado español en China, en donde la presencia es limitada en comparación con otros países occidentales. Mediante las Conclusiones, el artículo sugerirá conductas con objeto de sortear los condicionantes culturales que contribuyan a apoyar la gestión intercultural del empresario español y facilitar su actividad empresarial en el país asiático.

\section{DIMENSIÓN CULTURAL}

Los atributos culturales de un país determinan cómo las personas interactúan y se relacionan entre sí, con empresas e instituciones. Las diferencias en las creencias religiosas, las normas sociales, el pasado cultural y el idioma son capaces de crear distancias entre empresas según los países de las que sean originarias (Ghemawat, 2001). 
Hofstede y Bond (1988:6), definen la cultura como "la programación colectiva de la mente que distingue a los miembros de una categoría de personas de los de otra". Un conjunto específico de personas puede constituir un país, un grupo étnico, una organización, una familia o alguna otra unidad (Hofstede y Bond, 1988).

En su sentido más amplio, se refiere a los esquemas de interacción humana, y en su implicación en la gestión empresarial entre distintas culturas y trata del conocimiento de las personas para interpretar su experiencia y generar comportamientos sociales. Este conocimiento lo conforman los valores, actitudes y las influencias en el comportamiento.

Debido a la globalización económica y a una mayor presencia multinacional de empresas, la Gestión Multicultural ha cobrado una especial relevancia, especialmente en el crecimiento de la cooperación entre empresas de diferentes países, donde pueden surgir dificultades debido a sus diferentes antecedentes culturales y explica el esfuerzo de las empresas por alcanzar una Gestión Multicultural Cruzada, es decir, analizando el comportamiento de las personas en organizaciones presentes en distintas partes del mundo y aprendiendo a trabajar en organizaciones con empleados y colectivos de clientes de diferentes culturas (Adler, 2008).

Existe la necesidad de establecer unas pautas y herramientas de análisis específicas para evaluar las relaciones entre empresas chinas y empresas occidentales, debido a las especificidades de la cultura china y la dificultad en los medios de análisis utilizados en el entorno exclusivamente occidental (Deshun, 2016). La atención al contexto ha resultado especialmente relevante en los nuevos análisis realizados por Nisbett (Nisbett, 2003). Los occidentales viven en mundos sociales menos restrictivos, haciendo hincapié en la independencia que les permite prestar menos atención al contexto. Los orientales ven el mundo diferente a los occidentales, los efectos se extienden a cuestiones más abstractas, como las percepciones de causa y efecto. Con su enfoque en el individuo, los occidentales tienden a ver los acontecimientos como el resultado de agentes específicos, mientras que los planteados por los orientales consideran los acontecimientos en un contexto más amplio. El análisis como resultado de los crecientes vínculos y comunicación intercultural en las dos últimas décadas entre orientales y occidentales han generado nuevas percepciones de cómo funciona el mundo, habiendo aportado con ello beneficios para ambas culturas (Nissbett, 2003).

La cultura tiene una gran influencia en las percepciones. A pesar de que las personas pueden estar conscientemente tratando de evitar problemas, realizan inevitablemente juicios éticos, ya que se están comunicando. Cuando personas de distintas culturas aprenden a comunicarse, no sólo deben aprender el lenguaje hablado, sino también la gestión de las percepciones.

Aunque la gestión intercultural no sólo afecta a la comunicación e interacción directa entre personas, sino a los gustos, hábitos de consumo, imagen y aspecto, 
packaging, entre otros, en definitiva, el nivel de adaptación cultural con que la empresa accede al consumidor chino de forma global, es uno de los principales factores que condicionan el éxito o fracaso de las empresas extranjeras en China. ${ }^{2}$

Existen varios autores que han tratado de comprender los aspectos culturales y sus diferencias en la gestión inter-cultural con el objeto de desarrollar y mantener relaciones empresariales entre empresas y miembros de países culturalmente distintos (Hall y Hall, 1990); (Hofstede, 1993 y 2001), (Hofstede y Bond, 1989) y (Lewis, 2006).

Hofstede (Hosftede, 2001), explica que la cultura basada en los sistemas de valores se compone de cuatro dimensiones: La distancia de poder, el individualismo versus colectivismo, masculinidad versus feminidad y la aversión a la incertidumbre que se complementa con la investigación realizada por Bond y Hofstede (Bond y Hofstede, 1989) e identifica una quinta dimensión de características que denomina "oriental" e introduce, el corto plazo y el largo plazo.

Así mismo, Edward T. Hall (Hall y Hall 1990) presentó una serie de conceptos focalizados sucesivamente en el estudio de cómo las personas ven el mundo y cómo sus modelos culturales inconscientes determinan su interacción. Introduce el estudio de la percepción cultural y el uso del espacio. Determina los conceptos policrónico y monocrónico, en función de la habilidad de los individuos en atender a múltiples tareas de forma simultánea, en contraposición a la atención de tareas de forma secuencial, respectivamente.

También E. T. Hall (Hall y Hall, 1990) desarrolló un modelo contextual en el que combina la administración del tiempo y el espacio en la comunicación intercultural entre Culturas de Alto y Bajo Contexto.

Richard Lewis (Lewis, 2006) creó el Modelo Lewis, basado originariamente en los conceptos culturales de Edward T. Hall, policrónicos y monocrónicos. Incorporó e integró una acumulación de múltiples dimensiones. Amplió los conceptos iniciales de Hall y Hall (1990), los conceptualizó e integró en tres nuevas Dimensiones: Lineal-Activa, formado por grupos de individuos Orientados a las Tareas y a la Planificación, la dimensión Multi-Activa, Orientados a las Personas y al Diálogo y la Reactiva del Modelo, que identifica una personalidad en individuos Introvertidos y Oyentes respetuosos, que están Orientados a Escuchar.

\subsection{Orientación social y profesional china}

En la vida diaria de la persona china, existen dos sistemas interconectados, la persona y su entorno. Tal interconexión constituye la base del tipo de Orientación Social que trasciende y afecta a las relaciones empresariales.

2 Amat. J. (2016), "Factores Clave del Éxito en el Mercado Chino". Harvard Deusto, abril, 2016, pp. 57-67. 
En la sociedad china las relaciones se clasifican en tres niveles: Jiaren, se refiere a familiares; Shuren tiene que ver con relaciones de proximidad, como amigos, vecinos, compañeros de estudios y de trabajo y Shengren es la palabra y descripción que en China se utiliza para identificar a los extraños y desconocidos. Los distintos niveles sociales conforman una primera aproximación a la tipología de las conexiones sociales y empresariales en el país.

Los chinos ponen mucho énfasis en la aproximación y el trato, en forma de círculos concéntricos con alta entrega a los miembros de la familia o Jiaren, que están condicionadas por el mantenimiento de factores utilitarios y relacionales de afecto. Mientras que los Shuren, en los que no están involucrados lazos de consanguinidad, hay limitaciones en lo que una parte puede deber a la otra y ambas partes consideran como necesario y deseable un equilibrio moderado de intercambio de favores.

En cuanto al nivel denominado Shengren, se mantienen relaciones sociales teniendo en cuenta los beneficios que puede reportar la relación. En la interacción con las otras partes, tienden a realizar cálculos meticulosos y detallados de los resultados potenciales de sus transacciones y no desean realizar ni siquiera un pequeño sacrificio, especialmente en términos monetarios. Las partes son muy sensibles a los desequilibrios o injusticias de dar y tomar, y cuentan con altas expectativas de reciprocidad, especialmente cuando entran en contacto con personas desconocidas en la esfera empresarial.

En la gestión de las relaciones de dichos niveles existen diferencias importantes en el trato social y en el nivel de relación que mantienen las personas dependiendo de la categoría en que se encuentran. Los individuos chinos desarrollan habilidades y estrategias sociales para establecer, mantener y mejorar las relaciones útiles de carácter interpersonal que denominan "guanxi".

El guanxi es una palabra originaria de la cultura china que se puede traducir como "conexiones", "red personal" (Leung et al., 1995). Tener "guanxi" significa tener buenas conexiones, pero en un contexto típico chino, el guanxi va mucho más allá de las conexiones.

Se produce, mantiene y aplica en todos los aspectos de la vida cotidiana de un individuo chino dependiendo de la categoría en que se desarrolla la relación. En un contexto de negocios, el guanxi se refiere a un sistema chino de hacer negocios sobre la base de las relaciones personales, que es representativo de la forma en que se hacen los negocios en gran parte del mundo no-occidental (Lovett et al. 1999:231). El nivel de guanxi chino determina el impacto sobre la manera de participar en intercambios de información.

El guanxi es un aspecto cultural importante a la hora de hacer negocios en China. Desde la perspectiva académica (Leung et al., 1995) se ha tratado de explicar el proceso de construcción del guanxi. Muchas son las variables claves que pueden afectar a la adaptación de guanxi, tienen que ver con el intercambio de 
información y las expectativas mutuas. Dado que el intercambio de información es una variable clave en el guanxi, es de suponer que las personas con guanxi de mayor proximidad tienden a compartir más información (Leung et al., 1995).

A nivel empresarial existe la tendencia de aumentar y prolongar la reciprocidad en el intercambio de favores y estar dispuestos a seguir la misma regla para mostrar sinceridad. Además, se identifica que las relaciones familiares, la localidad y edad tendrán menos influencia en el futuro, mientras que aumenta la importancia en cuestiones económicas y políticas, mostrando la voluntad y capacidad para ofrecer ayuda y la voluntad incuestionable de generar confianza con las personas claves, funcionarios del gobierno y empresas privadas. Por lo tanto, el enfoque por mantener y mejorar una red existente de Guanxi, se centra en las preferencias y necesidades individuales de los socios dentro de la red (Jin, 2006).

Debido a que el guanxi juega un papel importante en las interacciones con el gobierno local y los procesos administrativos de aprobación de autorizaciones y licencias en China, de por sí ya muy burocráticos, las autoridades locales prefieren la familiaridad y atienden las solicitudes de forma aleatoria, por lo que el guanxi es una herramienta importante para asegurar la facilidad y revisiones rápidas de solicitudes, así como de resolución de incidencias con la Administración Pública. Un ejemplo habitual lo constituyen las cenas informales con funcionarios, las cuales generan guanxi y se utilizan como estrategias de gestión (Chen et al., 2011:3).

Mientras que en Occidente las transacciones sociales se consideran de forma general aisladas y puntuales, en China estas relaciones sociales se mantienen y refuerzan a través de interacciones continuas y a largo plazo (Ordóñez de Pablos, 2004:231), que son generadoras de guanxi.

\subsection{Autoridad y Jerarquía}

La Sociedad china cuenta con una Orientación Cultural Autoritaria, donde el padre tiene el poder absoluto en las normas que rigen en la familia. Las actitudes y comportamientos hacia el cabeza de familia son indiscutibles y son extensibles o generalizados a los responsables de grupos sociales u organizaciones, tales como el magistrado local y el emperador (identificado simbólicamente como el poder político máximo). Como resultado cultural de ello, las autoridades y los funcionarios del gobierno se identifican como substitutos del padre y por lo tanto les ofrecen la absoluta lealtad y obediencia. El sentido de autoridad patriarcal es el prototipo de autoridad oficial. Por otro lado, el gobierno toma toda clase de medidas, desde leyes formales hasta recompensas para reforzar la autoridad patriarcal. El chino tiende a ser muy sensible y aquiescente con todo tipo de autoridad.

Hay que considerar que la orientación social china es el producto de la tradicional economía agrícola del país y su estructura social agraria. A medida que el 
país evoluciona hacia actividades comerciales e industriales, la orientación social decrece con fuerza en la sociedad (Yang,1995).

La Dimensión de "La distancia al poder" (Hosftede, 2001), se identifica como la medida en que los miembros menos poderosos de las instituciones y las organizaciones aceptan que el poder está distribuido de forma desigual. Los países en los cuales la gente obedece ciegamente a sus superiores tienen una alta distancia al poder. China cuenta con un índice de $80^{3}$, mientras que España cuenta con 57 , lo cual refiere a que el alto índice de China indica que tiende a una mayor centralización y a la presencia de estructuras empresariales verticales, con mayor proporción de personal supervisor en los niveles más bajos de la estructura de la empresa. Mientras que en España existe una mayor descentralización empresarial, con una estructura más plana, menores niveles de personal de supervisión y mayor presencia de personal frecuentemente cualificado.

La responsabilidad en decisiones y negociaciones empresariales corresponde al profesional español, que ha sido nombrado y habilitado con las atribuciones correspondientes al objetivo asignado. Mientras que en el entorno chino, corresponderá a la persona de mayor responsabilidad en la empresa y habitualmente de mayor edad, lo que puede redundar en un desajuste jerárquico en las dos partes, pero coincidente en la capacidad de decisión de ambas.

\section{Tabla 1. Índices de Valoración de las Dimensiones Culturales entre España y China}

\begin{tabular}{|c|c|c|c|c|c|}
\hline & $\begin{array}{c}\text { Distancia } \\
\text { al Poder }\end{array}$ & Individualismo & Masculinidad & $\begin{array}{c}\text { Aversión a la } \\
\text { Incertidumbre }\end{array}$ & $\begin{array}{c}\text { Orientación a } \\
\text { Largo Plazo }\end{array}$ \\
\hline España & 57 & 51 & 42 & 86 & 19 \\
\hline China & 80 & 20 & 66 & 30 & 118 \\
\hline
\end{tabular}

Fuente: Adaptado de Geert Hofstede, Culture's Consequences, 2 2 Edición (Thounsand Oaks, CA: Sage,2001).

\subsection{Aversión al riesgo}

El Control de la incertidumbre indica hasta qué punto la gente se siente amenazada por situaciones ambiguas que generan creencias y crean instituciones que tratan de evitarlas.

\footnotetext{
${ }^{3}$ Los índices numéricos indicados en el artículo a partir de esta Nota al pie, se refieren a la Tabla 1 Índices de valoración de las dimensiones culturales de España y China. A más elevada numeración existe mayor aproximación al título de la dimensión.
} 
El alto nivel de España (índice 86) indica comportamientos de clara aversión a la incertidumbre. La cultura en los negocios cuenta con sistemas y procesos de gestión empresarial que convierte a las Organizaciones y empleados en dependientes y predecibles. Indica que las personas no desean aceptar riesgos y necesitan seguridad. A nivel empresarial los españoles tienen necesidad de estructurar las actividades con reglas escritas, los directivos toman menos riesgos, existe menor rotación de personal y los empleados son menos ambiciosos. Mientras que en China (índice 30), las actividades empresariales se encuentran menos estructuradas y con menos reglas escritas, con una mayor toma de riesgo en las decisiones de los Directivos y con una elevada tasa de rotación de personal en las empresas.

\subsection{Masculinidad}

Se define como una situación en la cual los valores dominantes en la sociedad son el éxito, el dinero y las cosas. Por el contrario, la feminidad es el término usado para describir una situación en la cual los valores dominantes en una sociedad se caracterizan en la calidad de vida y el cuidado de los demás.

En China existe un mayor índice de masculinidad (índice 66), lo que indica que los puestos de trabajo se caracterizan por un elevado nivel de tensión y muchos directivos creen que a sus empleados no les gusta el trabajo y deben estar sometidos a control.

Es una sociedad masculina, orientada y dirigida al éxito. La necesidad de asegurarse el éxito puede ser observada en la capacidad de sacrificio en muchas prioridades familiares y de ocio, en favor del trabajo.

El menor índice en España (42) indica la existencia de una mayor importancia en la cooperación, ambiente familiar y seguridad en el empleo. Los directivos ofrecen a sus empleados mayor confianza para que asuman responsabilidades y les permiten un mayor nivel de libertad. Ambas culturas cuentan con un nivel medio y próximo de masculinidad, por lo que la dimensión no identifica una brecha relevante en caracterización diferencial entre ambas.

\subsection{Individualismo versus Colectivismo}

Individualismo es la tendencia de la gente a cuidar de ellos mismos y proteger a sus familiares próximos, mientras que en una Sociedad Colectivista, la gente tiende a pertenecer a grupos o colectivos y cuidar unos de otros en un intercambio de lealtades.

Un mayor índice de individualismo de España (índice 51) indica una mayor iniciativa individual y promociones profesionales basadas en competencia profesional. Los profesionales son proclives a confiar en su propio criterio acerca de lo 
que deberían hacer, tienden a trabajar solos y suelen rechazar la cooperación, ya que constituye un signo de debilidad, valorando la independencia.

En China (índice 20) existe menor iniciativa individual y las promociones están basadas en la edad y antigüedad, que por sí mismas constituyen elementos de respeto y obediencia, es decir, China con bajo nivel de individualismo, cuenta con normas, valores y creencias colectivistas que influencian un gran número de las prácticas empresariales, entre las que se reflejan el nombramiento de Directivos en función del favoritismo debido a su pertenencia y lealtad a grupos, que también se aplica a la familia y amigos. Los directivos asumen un papel paternalista en la Organización y se encuentran cómodos cooperando unos con otros y evitando riesgos, al mismo tiempo que reducen responsabilidades.

Se cree que las actitudes de los empresarios hacia la cooperación se ven influenciadas por los valores culturales subyacentes de la sociedad y tienen un impacto en las diferencias estratégicas de cooperación en general (Weaver, 2000). El marcado perfil colectivista chino hace que dependan más de los grupos o instituciones para determinar lo que deben hacer y enfatizan la lealtad al grupo. Son más propensos a cooperar con otros para evitar riesgos y reducir responsabilidades. En sus sistemas de valores se aprecia el deber para con el grupo y la armonía entre sus miembros, mientras que la consecución de objetivos personales, se valora negativamente en la sociedad china. No obstante, los cambios experimentados por la sociedad china en su evolución hacia la economía de mercado, así como la influencia de los recientes cambios económicos y tecnológicos, han propiciado un cambio gradual en las nuevas generaciones hacia posiciones más individualistas (Zhang y Shavitt, 2003).

Los directivos españoles, de perfil individualista, se enfrentan directamente a los problemas y plantean las discrepancias y situaciones conflictivas de forma clara. Cuando surgen incidencias o problemas con otros, son reacios a invertir tiempo y esfuerzo necesarios para conseguir la ayuda de otras personas. Por el contrario, los directivos chinos, debido a su fuerte orientación colectiva y bajo nivel de aversión a la incertidumbre, utilizan formas indirectas de influencia que involucran la ayuda de un tercero, es decir, introducen la figura del mediador o intermediario para que facilite la resolución de conflictos (Bond y Hofstede, 1989).

El español mantiene un nivel medio alto de individualismo, que hace que las decisiones dependan principalmente de su propio punto de vista para saber y decidir sobre lo que debe hacer, lo que implica su tendencia a trabajar solo y rechazar la cooperación debido a su perfil independiente. Cuando encara los conflictos, prefiere usar la autoridad para suprimirlos o arreglar las cosas en privado, mientras que los chinos prefieren resolver los conflictos mediante la negociación y el compromiso.

La importante brecha entre la capacidad de decisión individual del español y la necesidad del chino por compartir las decisiones con el grupo, generan ritmos distintos en la evolución de negociaciones y decisiones empresariales. 


\subsection{Orientación a largo plazo}

La dimensión denominada "Dinamismo Confuciano" (Hofstede y Bond,1988), indica el grado en que las personas y las organizaciones aplazan el logro de sus objetivos para alcanzar el éxito a largo plazo.

La Orientación a largo plazo describe y caracteriza esta dimensión, en donde la persistencia y la perseverancia son atributos que se valoran muy especialmente. Fomenta las virtudes que están orientadas a conseguir recompensas futuras, entre ellas el ahorro. Mientras que el corto plazo fomenta las virtudes del pasado y del presente. Ve la verdad como absoluta y contempla cortos ciclos de consecución de realizaciones y resultados.

La orientación a largo plazo en China, con el índice de 118, es el más elevado de los perfiles identificados en el ranking (Hofstede y Bond, 1988), e indica el "horizonte de tiempo" de la sociedad china y la importancia atribuida al futuro, que se caracteriza por la lentitud de los procesos y el establecimiento de relaciones, buscando el conocimiento y experiencia con empresas e interlocutores.

El bajo índice de España de 19 en la orientación al largo plazo, la coloca en el segmento más bajo del ranking de la dimensión. Indica el cortoplacismo y la inmediatez con los que actúan las empresas españolas en su búsqueda de resultados empresariales, en contraposición al nivel más elevado de China, lo que implica una importante brecha entre ambas culturas y distintas perspectivas temporales en sus relaciones empresariales.

El desajuste tiene que ver con la visión del empresario español en la necesidad de tomar decisiones y conseguir rápidos e inmediatos resultados. Mientras que la parte china considera una lenta y cauta aproximación de conocimiento mutuo y de confianza entre las partes, como recorrido necesario en el establecimiento de relaciones profesionales de larga duración.

\subsection{Percepción del tiempo}

Se refiere a la gestión de las expectativas relacionadas con la programación, planificación, agendas y todo lo que tiene que ver con la puntualidad en el trabajo y en reuniones. Hall y Hall (1990) describen en cómo las culturas y las sociedades difieren en su percepción del tiempo.

Las sociedades monocrónicas o lineales se caracterizan por estar orientadas al tiempo, que es considerado como un recurso y cuentan con una visión rígida en la programación y la puntualidad. La gestión empresarial en esta cultura ve el tiempo como un concepto lineal, donde se gestiona secuencialmente, donde los compromisos, plazos, la programación de reuniones y actividades deben ser respectadas escrupulosamente. La perspectiva de la gestión empresarial cuenta con una visión cortoplacista cuando se trata de inversiones y de resultados. 
En los países con una gestión policrónica del tiempo, la gente es capaz de gestionar distintas actividades simultáneamente y la comunicación es circular, con largos periodos en la toma de decisiones y con un concepto relativo y flexible de la puntualidad. La gestión empresarial se caracteriza por ofrecer un alto valor a las relaciones y el tiempo necesario en establecerlas, ya que su horizonte es a largo plazo. Se evita programar los tiempos estrictamente, su gestión se caracterizará por la relajación en el cumplimiento de los programas y en la gestión del tiempo.

Las culturas del Sur de Europa (entre ellas la española) se consideran más próximas a una identificación policrónica que monocrónica, mientras que la China es considerada por definición el prototipo típico de cultura policrónica (Lewis, 2013), (EL-Guindy, 2013), lo que indica una relativa aproximación entre ambas en cuanto a percepción del tiempo.

\subsection{La comunicación}

La complejidad de la comunicación intercultural se refiere a la forma en que se comunican los mensajes dentro de una sociedad y de cómo ambos grupos perciben la realidad (Matthews, 2005).

En Hall y Hall (1990), se identifican distinciones entre culturas de Alto Contexto (Oriental) caracterizada en China y Bajo Contexto (Occidental). España es considerada de Medio Contexto (Dozier et al., 1998)

La interpretación de los mensajes en las culturas de Alto Contexto se apoya en gran medida en claves contextuales, es decir, lo que no se dice, a menudo, es tan importante (si no más) como lo que se dice.

La comunicación se ve como un medio para crear una relación fluida y armoniosa. Los individuos en una Cultura de Alto Contexto, prefieren un lenguaje indirecto y educado para poner de relieve el sentido mutuo de precaución y respeto por los demás. Evitan avergonzar y ofender a otros, por lo que podría explicarse la renuencia de la cultura china a decir "no" cuando desean expresar un desacuerdo. Los chinos tienden a mantener la voz suave y son especialmente sensibles a las señales de comunicación y al énfasis en los mensajes no verbales. La cultura china constituye el paradigma de Alto Contexto en la que mostrar impaciencia, frustración, irritación o enfado rompe la armonía y se considera grosero y ofensivo. Los acuerdos se basan en la confianza y entienden que pueden ser modificados, ya que no son estáticos y pueden evolucionar en el tiempo.

En la cultura occidental de Bajo Contexto, los individuos se expresan verbalmente y ponen especial énfasis en el lenguaje hablado. La principal función en la cultura occidental es la de expresar ideas y pensamientos de manera clara, lógica y de forma tan convincente como sea posible. La comunicación es directa y explicita y los significados son sencillos. Se tiende a valorar los 
conocimientos y los resultados de las negociaciones de manera eficiente. Estas culturas utilizan específicamente los contratos escritos para cerrar acuerdos, otorgándoles efectos legales.

El posicionamiento de Medio Contexto del empresario español podría facilitar la comprensión y aproximación a la cultura china de Alto Contexto.

\subsection{Reuniones y negociaciones}

Richard Lewis (Lewis, 2006) identificó y desarrolló tres categorías de personalidad basada exclusivamente en el "comportamiento", que las denominó Lineales-Activas, Multi-Activas y Reactivas (Tabla 2).

Mientras que la personalidad Multi-Activa se identifica principalmente en países del Sur de Europa y Mediterráneos; España se halla clasificada en la centralidad de la categoría.

Describe la personalidad Multi-Activa como de personas emocionales, locuaces e impulsivas que muestran un gran entusiasmo, tratando de convencer, creando un entorno positivo y generando dialogo en las relaciones. Dan mucha importancia a la familia, los amigos y las relaciones. En general, les gusta hacer varias cosas a la vez y son poco rigurosas con la programación y gestión de los tiempos.

La personalidad Reactiva se localiza en los principales países del Este de Asia, en donde la centralidad de la categoría la ocupan Vietnam y China.

\section{Tabla 2. Comportamientos característicos en Negociaciones y Reuniones de individuos de Personalidad Multi-Activa: Española y Reactiva: China}

\begin{tabular}{|c|c|}
\hline Multi-Activa: Española & Reactiva: China \\
\hline Hablan la mayor parte del tiempo & Escuchan la mayor parte del tiempo \\
\hline Extrovertidos & Introvertidos \\
\hline Muestran los sentimientos & Disimulan los sentimientos \\
\hline Inquisitivos & Respetuosos \\
\hline A menudo interrumpen & Muy orientado a las personas \\
\hline Orientados a las personas & Se muestran diplomáticos sobre la verdad \\
\hline Consideran que la verdad es flexible & Sontes \\
\hline Son Impacientes & Utilizan las conexiones \\
\hline Su lenguaje corporal es ilimitado & corporal es sutil y comedido \\
\hline Buscan la persona clave &
\end{tabular}

Fuente: adaptado de Richard Lewis. (2006) When Cultures Collide: Leading Across Cultures ( $3^{\text {a }}$.ed.) Nicholas Brealey Publishing, Boston, USA. 
Los individuos que forman parte de la categoría de personalidad Reactiva se identifican como buenos oyentes, que difícilmente iniciarán discusiones, ya que prefieren escuchar y conocer la posición de los otros antes de formarse una opinión, a partir de la cual reaccionarán.

Tratarán de armonizar la relación de forma paciente y con una perspectiva en el largo plazo, focalizando los planteamientos en problemas o proyectos con una perspectiva holística.

\section{CONCLUSIONES}

Los principales retos que deberán afrontar los empresarios españoles en China tienen que ver tanto con la gestión interna en las empresas, como con su entorno local chino en aspectos y barreras de carácter cultural.

Las siguientes conclusiones definen y sugieren conductas recomendables con el objeto de aproximar las distancias culturales entre empresarios y profesionales chinos y españoles:

3.1. El empresario chino sustenta tanto sus interacciones personales como empresariales en la amplitud de conexiones, es decir, un potente guanxi en el que pone a las personas primero, antes de llevar a cabo cualquier acuerdo, ya que considera que la amistad motiva y ayuda a establecer la relación adecuada que facilita el buen fin en contratos y negocios. Los empresarios chinos enfatizan su Orientación a las Relaciones como un medio de mejorar la productividad en la consecución de sus objetivos. Crean un entorno adecuado, sin poner límite al tiempo en el desarrollo de la confianza como origen del éxito en los negocios. La sospecha y la desconfianza caracterizan las reuniones con extraños. En las relaciones empresariales, la confianza debe ganarse, ya que las relaciones empresariales no pueden materializarse sin ella.

Es por ello que cualquier aproximación empresarial española a China debe entender la necesidad de establecer sólidas conexiones, apoyándose preferentemente en la figura del intermediario, como elemento inicial necesario de interacción social y profesional. Por lo que generar confianza, deberá constituir la prioridad para establecer un guanxi propio o unas conexiones locales en los ámbitos empresarial y gubernamental. Dicha confianza será el centro de la red de conexiones, que sólo podrá generarse mediante la aplicación de una estricta reciprocidad en la prestación de apoyos y favores a los miembros de red.

3.2. La jerarquía, autoridad y poder conforman la estructura de la sociedad china, es por lo que cualquier interrelación entre chinos y españoles debe mantenerse entre iguales jerárquicos en un entorno de estatus profesional. El desajuste de estatus jerárquico entre representantes de empresas china y española, no sólo dificulta la interlocución entre distintos niveles jerárquicos, sino que limita el 
buen fin de cualquier acuerdo, pudiendo ser interpretado por el empresario chino como un desaire al mantener relaciones profesionales con interlocutores de menor status, aunque cuenten con las atribuciones y autonomía necesarias para tomar decisiones empresariales. Los interlocutores chinos de alto nivel jerárquico, son los únicos que toman decisiones importantes, limitándose el papel de los mandos medios a simples transmisores de decisiones y responsables de su ejecución.

3.3. La gestión de las entrevistas, reuniones y relaciones deben plantearse con toda la disponibilidad de tiempo que sea necesario, observando un riguroso protocolo y formas suaves de interlocución, con prolongadas introducciones de índole personal que forman parte del ritual que permite una aproximación personal y social de las partes, como primer paso en el conocimiento mutuo de las personas y una condición inexcusable para el buen fin de cualquier iniciativa empresarial posterior.

En las exposiciones se sugiere que el español entienda la necesidad de controlar la emotividad y la expresividad que lo identifican caracterológicamente. El tono de voz debería ser pausado y de bajo volumen, evitando la contundencia verbal, ya que podría ser entendida como una muestra de enfado y agresividad. El lenguaje no verbal o gesticulación excesiva pudiera ser interpretada como una muestra de frustración y enfado. La parte china muestra especial atención a la exposición verbal y atención a los signos no verbales del español. Escucha con mucha atención, ya que desea no solo conocer los motivos y razonamientos de la parte española, sino valorar el grado de confianza que transmite el interlocutor en su forma de expresión, como elemento básico para mantener relaciones empresariales de futuro.

En las reuniones, el interés del español en mantener un programa con una evolución secuencial de temas y cuestiones a tratar se puede ver desbordado por la gestión circular de los distintos puntos y una visión holística de los planteamientos. El profesional español no debería mostrar impaciencia ni rechazo directo a planteamientos del lado chino. Cuando surgen discrepancias en aspectos inaceptables por la parte española, se debería responder con evasivas, en vez de "rotundos noes" con objeto de mantener la armonía que debe caracterizar unas relaciones duraderas, que va más allá de una simple negociación o acuerdo.

Cualquier evasiva es interpretada como una negación sin confrontación, que permite mantener la armonía de los interlocutores y el buen fin de las relaciones futuras.

Se sugiere que cualquier cambio de opinión sobre acuerdos o impresiones anteriores, no sea confrontado con la parte china como forma de salvar la cara y prestigio del interlocutor chino. Los acuerdos alcanzados no suelen ser definitivos y se encuentran sujetos a modificaciones posteriores, entre otros motivos, porque la parte china comparte la información y debate sobre ella, valorando posiciones y puntos de vista de su colectivo. 
Aunque existan acuerdos escritos y firmados, el empresario chino considera que son dinámicos en el tiempo y están sujetos a posibles modificaciones que pudieran ser fruto de acontecimientos o incidencias imprevistas en el entorno económico, político o social.

\section{BIBLIOGRAFÍA}

ADLER, N. (2008), International dimensions of organizational behavior ( $5^{\mathrm{a}}$ edición), Cincinnati, Ohio: South-Western.

ALDAMA, Z. (2014), "El calvario chino: Algunas empresas españolas abandonan el país por sus dificultades", El País, 9 de Febrero.

AMAT. J. (2016), "Factores Clave del Éxito en el Mercado Chino". Harvard Deusto, abril, 2016. núm. 255, pp. 57-67.

BOND, M. H. y HOFSTEDE, G. (1989), "The Cash Value of Confucian Values", Human Systems Management, vol.8, núm. 3, pp. 195-200.

CACHO, L. (2006), "Presencia Económica Española en China: Perspectivas Para el Futuro", en Economía Exterior (ed.), La Presencia Española en Países de Fuerte Crecimiento: China e India, Estudios de Políticas Exteriores, Madrid, pp. 85-159.

CHEN, J. et al. (2011), "Risky Business: Private Equity in China", Risky Business: Private Equity in China en Knowledge@Wharton, de 26 de Enero de 2011. Obtenido el 7 de Mayo de 2012 de http://knowledge.wharton. upenn.edu/article.cfm?articleid $=2687$

DESHUN, L. (2016), On Chinese Culture, $1^{a}$ ed. 2016, Heilongiiang Education Press \& Springer Science+Business Media, Singapore.

DELOITTE (2015), 2016 Global Manufacturing Competitiveness Index, U. S. Council on Competitiveness and Deloitte Touche Tohmatsu Limited, UK.

DOZIER, J. B. et al. (1998), "Need for approval in low-context and highcontext cultures: A communications approach to cross cultural ethics", Teaching Business Ethics, vol. 2, núm. 2, pp. 111-125.

FANJUL, E. (2016), "Asia, una asignatura pendiente para las empresas españolas". Elcano, Real Instituto, Economía internacional 21.04.2016. Obtenido el 18 de Julio 2016 de http://www.blog.rielcano.org/asia-unaasignatura-pendiente-para-las-empresas-espanolas/.

EL-GUINDY, B. (2013), "Conflicting cultures", myGuidon.com, 4 April 2013, obtenido el 13.01.2016, http://www.myguidon.com/index. php?option=com_content $\&$ task=view $\&$ id $=15844$.

GARCÍA-TAPIA, J. L. (2009), "Presencia (y ausencia) Española en China hasta 1973" en Relaciones bilaterales con China, Boletín Económico de ICE, núm. 2972, del 1 al 15 de septiembre, pp. 71-93. 
GHEMAWAT, P. (2001), "Distance still matters", Harvard Business Review, September, 2001.

HALL, E. T. y HALL, M. R. (1990), Understanding cultural differences, Intercultural, Yarmouth, ME.

HOFSTEDE, G. (1991), Cultures and Organizations: Software of the Mind, McGraw-Hill, London.

HOFSTEDE, G. (1993), "Cultural Constraints in Management Theories", Academy of Management Executive, vol. 7, núm. 1, pp. 81-94.

HOFSTEDE, G. (2001), Culture's consequences: comparing values, behaviors, institutions, and organizations across nations, $2^{\mathrm{a}}$ ed., Sage, Thousand Oaks.

HOFSTEDE, G. y BOND, M. (1984), "The need for synergy among cross-cultural studies", Journal of Cross Culture Psychology, vol. 15, núm. 2, pp. 417-433.

HOFSTEDE, G. y BOND, M. H. (1988), "The Confucius connection: from cultural roots to economic growth", Organizational Dynamics, vol.16, núm. 4, pp. 4-21.

HOUSE, R. J. et al. (2004), Culture, leadership, and organisations: The GLOBE study of 62 Societies, Sage Publications, London.

JIN, A. (2006), "Guanxi Networks in China: Its Importance and Future Trends", China Ë World Economy, vol. 14, núm. 5, pp. 105-118.

LANE, H. y BEAMISH, P. (1990), "Cross-cultural co-operative behaviour in joint ventures in LDCs' ”, Management International Review, núm.30, pp. 87-102.

LEUNG, T. K. P. et al. (1995), "Adaptation and the Relationship Building Process in the People's Republic of China (PRC)", Journal of International Consumer Marketing, vol. 8, núm.2, pp. 7-19.

LEWIS, R. D. (2006), When Cultures Collide: Leading across cultures, $3^{\text {a }}$. ed., Nicholas Brealey Publishing, Boston.

LEWIS, R. D. (2013), "Monochromatic and Polychromatic Cultures", 21.01.2013, obtenido el 12 de Enero 2016 de: http://blog.crossculture. $\mathrm{com} /$ crossculture/2013/01/monochromatic-and-polychromatic-cultures. html.

LOVETT, S. et al. (1999), "Guanxi versus the market: Ethics and efficiency", Journal of International Business Studies, núm. 2, pp. 231-247.

MATTHEWS, R. (2005), "Where east can never meet west", Financial Times, ft.com/management, obtenido el 21.01.2013: http://www.ft.com/cms/ s/1/8de93a80-418d-11da-a45d-00000e2511c8.html\#axzz3x90N5nlm) 20 Octubre de 2005.

NISBETT, R. E. (2003), The Geography of Thought: How Asians and Westerners Think DifferentlyAnd Why, The Free Press, New York.

ORDÓÑEZ DE PABLOS, P. (2004), "La importancia de guanxi, renqing y xinyong en las relaciones empresariales en China: Implicaciones para las 
empresas españolas", Información Comercial Española, ICE Revista de Economía, núm. 818, pp. 221-233.

ROTH, A. V. et al (2010), "2010 Global Manufacturing Competitiveness Index", U. S. Council on Competitiveness and Deloitte Touche Tohmatsu Limited, UK. June.

THE WORLD FACTBOOK. Central Intelligence Agency (2016): "Country Comparison: Exports”. Obtenido el 15 de Julio 2016. https://www.cia.gov/ library/publications/the-world-factbook/rankorder/2078rank.html.

UNCTAD (2016), World Investment Report 2015, United Nations Publication. Obtenido el 16 de Julio de 2016 de unctad.org/en/PublicationsLibrary/wir2015_en.pdf.

WANG, B. X. \& CHEE, H. (2011), Chinese Leadership, Palgrave Macmillan, New York.

WEAVER, K M. (2000), "Attitudes toward Cooperative Strategies: A CrossCultural Analysis of Entrepreneurs", Journal of International Business Studies, núm.31, Fourth Quarter, pp. 591-609.

YANG, K. S.(1995), "Chinese Social Orientation-An integrative analysis", en Lin, T. Y; Tseng, W. S. y Yeh, Y. K. Chinese Societies and Mental Health, Oxford University Press, Hong Kong, pp. 19-39.

ZHANG, J. y SHAVITT, S. (2003), "Cultural values in advertisements to the Chinese x-generation", Journal of Advertising, vol. 32, núm. 1, pp. 23-33. 